\title{
Next Generation Sequencing
}

National Cancer Institute

\section{Source}

National Cancer Institute. Next Generation Sequencing. NCI Thesaurus. Code C101293.

Technologies that facilitate the rapid determination of the DNA sequence of large numbers of strands or segments of DNA. 